\title{
El Bicentenario de Paraguay como ejemplo de la didáctica de la Historia
}

The Bicentennial of Paraguay like an example of the didactic of History

José Manuel Rodríguez Pardo*

\section{Resumen}

En El Bicentenario de Paraguay como ejemplo de la didáctica de la Historia defendemos que, lejos de ser una ciencia positiva a la altura de las matemáticas - la química, la historiografía fue siempre un verdadero ejemplo de lucha entre diversas posiciones que sobre un mismo hecho han mantenido diversos historiadores. La reciente celebración de los bicentenarios de independencia de las repúblicas hispanoamericanas, y de la república del Paraguay en particular, constituyó un ejemplo paradigmático de la Historia como disciplina cuya unidad doctrinal es polémica. Este artículo se consagra a analizar las diversas perspectivas que sobre el proceso de la independencia paraguaya se han sostenido, poniendo énfasis en la importancia de partir de las mismas para evitar enfoques dogmáticos o claramente partidistas.

Palabras clave: Historiografía, Paraguay, Bicentenario, Historia.

\begin{abstract}
In The Bicentennial of Paraguay like an example of the didactic of History we defend that History is not a positive science as mathematics or chemical, but historiography were always a true example of fighting between different points of view of differents historians. The recent celebration of the bicentennials of independence of hispanic republics, and particularly about of the republic of Paraguay, a paradigmatic example of History like a discipline which doctrinal unity is polemic. This work is dedicated to analyse the different points of view about the Independence of Paraguay, stressing specially in the importance of taking seriously all of this positions for avoiding dogmatic or partidist approachs.
\end{abstract}

Keywords: historiography, Paraguay, bicentennial, history.

*Universidad de Oviedo (España); Departamento de Filosofía

Correo electrónico: jmrodriguezpardo@gmail.com

Recibido: Octubre 2016

Aceptado: Noviembre 2016 


\section{Artículos de colaboradores extranjeros}

\section{INTRODUCCIÓN}

\section{LA PROBLEMÁTICA DEL BICENTENARIO PARAGUAYO}

El año 2011 se celebró con todos los fastos posibles el Bicentenario de la Independencia del Paraguay, que oficialmente se sitúa en las jornadas del 14 y 15 de mayo de 1811, momentos en los que:

"el sentimiento de independencia hacía grandes progresos en el Paraguay, y los partidarios de la emancipación comprendieron, que para fundarla bastaría proclamarla. De este modo fue que una revolución pacífica, bajo la dirección de José Gaspar de Francia y sostenida por las tropas a las órdenes del Comandante Pedro Juan Caballero, puso fin, el 14 y 15 de Mayo de 1811, a la dominación española." (Graty, 1862, p.57-8).

Sin embargo, no son pocos los autores que afirman que el 14 y 15 de mayo de 1811 no se proclamó independencia alguna, sino una Junta en defensa de los derechos del Rey de España Fernando VII; que el verdadero bicentenario debía situarse en rigor en la fecha del 12 de octubre de 1813, momento en el que precisamente el historiador norteamericano Richard Alan White, quien sostiene que Paraguay se independizó de "sus dos metrópolis", esto es, España y Buenos Aires:

"En su día final, 12 de Octubre, el congreso ratificó oficialmente 'el plan de gobierno propuesto por el Dr. Francia'. [...], proclamando enfáticamente la soberanía e independencia del Paraguay de sus metrópolis [España y Buenos Aires], anuló la calidad provincial, proclamando al Paraguay como una República." (White, 1989, p. 66).

El propio Richard Alan White afirmó, en un evento celebrado el 12 de octubre de 2011 en Asunción, en el contexto de los fastos oficiales del Bicentenario del Paraguay, que en ningún lugar como en el Paraguay se había falsificado tanto la Historia, ya que el verdadero bicentenario habría de celebrarse en 2013, la fecha que se mantuvo como oficial durante la época del Doctor Francia y los López, hasta que los denominados "legionarios", los paraguayos que participaron junto con los argentinos en la Guerra de la Triple Alianza para derrotar al gobierno del Mariscal López, como gobierno títere de los argentinos, instauraron en 1870 la fecha del 14 y 15 de mayo como efeméride de la independencia.

En aquella ocasión, mostró un decreto firmado el 7 de octubre de 1848 por Carlos Antonio López que establecía el 12 de octubre de 1813 como el Día de la Independencia Nacional, en conmemoración del Congreso que proclamó la soberanía nacional. Un documento que expresamente afirma lo siguiente:

“¡Viva la República del Paraguay!

¡Independencia o muerte!

El Presidente de la República. 
Considerando:

$1^{\circ}$ Que desde el Congreso de Julio de 1810, el Paraguay quedó libre del Gobierno de Buenos Aires.

$2^{\circ}$ Que la Independencia del Paraguay, fue reconocida explícitamente por el gobierno de las Provincias Unidas del Río de la Plata, en notas oficiales de 28 de Agosto, y $1^{\circ}$ de Octubre de 1811, y por el tratado de 12 de Octubre del mismo año.

$3^{\circ}$ Que en Octubre de 1813, el Paraguay ha proclamado su Soberanía nacional, declarándose independiente de hecho, de derecho de todo poder extraño.

\section{Decreta.}

Artículo $1^{\circ}$. En las comunicaciones oficiales, seguidamente a la salutación patriótica, ordenada por Decreto de 28 de Junio de 1845, se expresarán los años de libertad, e independencia, que cuenta la República, diciendo, año 39 de la libertad, 38 del reconocimiento explícito de la Independencia por el Gobierno de Buenos Aires, y 36 de la Independencia Nacional.

Artículo $2^{\circ}$. Publíquese, y dése al Repertorio nacional.

Asunción, Octubre 7 de 1848.

Carlos Antonio López." (López, 1848, p. 3-4).

Debido a que las fechas de libertad, independencia de Buenos Aires e independencia nacional, que aparecen en documentos como el citado más arriba oscurecen sumamente la cuestión, diversos historiadores han decidido que la independencia del Paraguay no sería propiamente una fecha, sino un proceso. Tal es el caso de Herib Caballero Campos, quien sostiene una visión que pretende aglutinar todos los hitos polémicos de la independencia de esta república hispanoamericana, dentro de un proceso que comenzaría con las reformas borbónicas en lo relativo a la formación del Virreinato del Río de la Plata, de 1776 en adelante, prosiguiendo con la revolución del 14 y 15 de mayo de 1811 y la proclamación de la independencia del año 1813 (con una suerte de epílogo consistente en la ratificación de la independencia por Carlos Antonio López un 25 de noviembre de 1842), siguiendo una idea ya difundida por autores como Julio César Chaves (Chaves, 1961):

"A partir de los acontecimientos de 1811 en adelante, se emprendió la empresa de construir una nación, el Paraguay. En este sentido creemos que dicho proceso se vio facilitado por las características geográficas y por sobre todo por la particularidad lingüística, pues el guaraní era el idioma hablado por todos.

Dicho proceso de la construcción de la nación se irá consolidando a lo largo de los años y por sobre todo mediante diversos mecanismos similares a los aplicados en los demás lugares del mundo en donde la nación de tipo liberal o estado nación se fue organizando como modelo ideal de las sociedades políticas. 


\section{Artículos de colaboradores extranjeros}

Son diversos los mecanismos utilizados con el fin de lograr dicho objetivo, además el camino no fue fácil pues durante los primeros cuarenta años las relaciones con Buenos Aires y otras provincias fueron sumamente difíciles.

En este sentido debemos ser conscientes de que la existencia del Paraguay como nación independiente no es un hecho natural, sino que es el resultado de la decisión de miles de personas que expresaron su voluntad a través de las Asambleas que se organizaron a lo largo de todo el territorio durante el mes de septiembre de 1813 y que finalmente expresarían su voluntad en el Congreso reunido en Asunción desde el 30 de septiembre hasta el 12 de octubre de 1813.

Lamentablemente las actas de dichas elecciones y los nombres de la gran mayoría de los diputados de dicha solemne Asamblea se han perdido.

Dicha fecha debe ser incorporada como trascendental, pues debemos conmemorar la decisión de los diputados del Paraguay que en ese día si bien no explícitamente, decidieron que la Provincia ya no esperase de Buenos Aires, la voluntad de construir una federación entre iguales y así mismo constituyó un gobierno que gobernaría sus destinos sin necesidad a recurrir a la legitimidad del rey cautivo, con lo que el Paraguay en dicho acto se independizaba de España y de Buenos Aires.

Queda claro que las principales reivindicaciones comerciales de la Junta Paraguaya fueron ignoradas por los gobiernos de Buenos Aires, actitud que finalmente llevaría de la autonomía inicial a la independencia, comprendiendo que dicha decisión no fue intempestiva ni automática, sino que fue el resultado de una consciente resolución de los líderes paraguayos, que lograron imponer su punto de vista ante la evidencia de los hechos." (Caballero, 2010, p. 127-8).

Sin embargo, esta idea procesual deja muchas incógnitas. La principal problemática es fácil de apreciar a la luz de los propios acontecimientos que sucedieron desde 1811 en adelante: quienes realizaron la revolución del 14 y 15 de mayo de 1811 en Asunción, publicaron dos días después "un bando, que daba a conocer la instalación del nuevo gobierno y sus propósitos, que no eran los de entregar la provincia a ningún extraño poder y sí conservarla para D. Fernando VII" (Garay, 1896, p. 163), con lo que su idea al deponer al gobernador Bernardo de Velasco no era la de declararse independientes de España, sino que además buscaba mantenerse en la órbita de Buenos Aires; de hecho cuando Velasco accedió a las ocho de la mañana de aquel 15 de mayo a convocar el Cabildo y cumplir las condiciones impuestas por los revolucionarios, "después de lo cual izaron una bandera en la Plaza, con salva de 21 cañonazos gritando todos iviva la Unión!" (Vittone, 1960, p. 187). Esto es, la unión con Buenos Aires y su revolución de 25 de mayo de 1810, también realizada en nombre de Fernando VII.

Como señaló Efraím Cardozo, las jornadas de mayo de 1811 fueron en realidad una revolución que quería hacerse estallar el 25 de mayo, como imitación de la que había tenido lugar un año antes en Buenos Aires, acelerada antes las 
noticias que afirmaban que el Gobernador Velasco sometía la provincia del Paraguay a los portugueses:

"Si hubo quienes todavía vacilaban en las filas paraguayas sobre el partido a tomar, ya no dudaron cuando el 13 de mayo cundió la noticia de la actitud de la clase gobernante. La connivencia con Portugal, bajo el manto de la princesa Carlota Joaquina fue así la causa ocasionante de la revolución, que ya nada ni nadie, pudo detener y que estalló el 14 de mayo de 1811." (Cardozo, 1954, p. 379).

Y, como bien aclara Ricardo Scavone Yegros al iniciar el relato del Segundo Consulado, el formado por Mariano Roque Alonso y el abogado Carlos Antonio López en 1841,

"Se ha sostenido que el movimiento emancipador paraguayo de 1811 perseguía al principio únicamente mayor autonomía y el derecho de autodeterminación frente al gobierno constituido en Buenos Aires, y que la influencia de Francia, sumada obviamente a otros factores, condujeron a la proclamación de la República en 1813." (Scavone, 2011, p. 15).

Salvando al Doctor José Gaspar Rodríguez de Francia, que como bien señaló José Antonio Vázquez en 1961, su biografía constituye la misma independencia del Paraguay -"La independencia del Paraguay es el Doctor Francia" (Vázquez, 1975, p. 29)-, todos los denominados "próceres de la independencia", tales como Fulgencio Yegros, Pedro Juan Caballero, Fernando de la Mora pretendían mantener la provincia del Paraguay unida a Buenos Aires, postulando su presencia en un hipotético congreso de lo que más tarde se denominaría como Provincias Unidas del Río de la Plata en 1816 (de las que este año se cumplen justamente doscientos años el 9 de julio, fecha de su congreso fundacional), y todos ellos fueron aplastados por el más ilustre hijo de la provincia ya ejerciendo de Supremo Dictador de la República del Paraguay, en 1820.

Entonces, el denominado "proceso" queda en evidencia, al no existir como tal unos próceres de la independencia o héroes de la patria, si excluimos precisamente al Doctor Francia, a quien la élite criolla de Asunción intentó derribar de forma fallida el citado golpe contra el Doctor Francia en 1820. Además, el bicentenario de Paraguay, de fijarlo en 2013, como afirma Richard Alan White, no es el de una república ya definida en sus límites territoriales, ya que al proclamarse un 12 de octubre de 1813, en la efeméride del descubrimiento de América, partía de la base de que el Paraguay, como bien supo detectar, en este caso despectivamente el afrancesado Nicolás Herrera, emisario de Buenos Aires, formaba "un imperio sin igual" (Vázquez, 1975, p. 99). Idea que ya venía de dos años atrás, puesto que en la Nota enviada por la Junta Gubernativa de Paraguay el 20 de julio de 1811 a la Junta de Buenos Aires, no se sugiere propiamente la independencia de una nación aislada del resto, sino la idea de la unidad continental americana, postulada por el 


\section{Artículos de colaboradores extranjeros}

principal protagonista de la independencia paraguaya, el Doctor José Gaspar Rodríguez de Francia:

"La confederación de esta provincia con las demás de Nuestra América, y principalmente con las que comprehendía la demarcación del antiguo Virreinato, debía ser de un interés más inmediato, más asequible y por lo mismo más natural, como de pueblos no sólo de un mismo origen, sino que por el enlace de particulares y recíprocos intereses, parecen destinados por la naturaleza misma a vivir y conservarse unidos." (Chaves, 1946, p. 103).

Esto es, tomaba como referencia los límites establecidos por el Imperio Español en América, a "Nuestra América", en el proceso de independencia. Como señala con cierta ironía Augusto Roa Bastos en su magna obra Yo el Supremo:

"Si se ha de formar un centro de unidad, ese centro no puede ser otro que el Paraguay. Núcleo de la futura confederación de Estados libres e independientes. ¿Por qué Buenos Aires no ha de venir a incorporarse al Paraguay? Centro-modelo de los Estados que han de confederarse. Lo fue desde el comienzo de la colonización. Con más razón debe serlo desde el comienzo de la descolonización." (Roa Bastos, 2005, p. 344).

Es decir, la República del Paraguay proclamada el 12 de octubre de 1813 es como las Provincias Unidas del Río de la Plata proclamadas en Tucumán en 1816 o la Gran Colombia de Simón Bolívar de 1819: estados independientes que refieren sus límites a la propia estructura virreinal marcada por España previamente, y que intentan mantener la unidad del continente. Sin embargo, como los procesos de independencia fueron realizados de forma no coordinada y tampoco los próceres de la independencia pudieron acordar la formación de una única nación, el resultado fue la descomposición paulatina, hasta formarse el mosaico de repúblicas hispanoamericanas que conocemos hoy día.

¿Puede pasarse por alto, como de hecho hacen los historiadores de toda condición, que el 12 de octubre de 1813, en el que el Doctor Francia proclamó la independencia de "la primera República del Sud", es la efeméride del descubrimiento de América por Cristóbal Colón? Solo desde posiciones claramente partidistas podría minimizarse este hecho. Aparte que no podemos olvidar que esa misma efeméride fue elegida por Francia para firmar nada menos que un tratado previo con Buenos Aires, el 12 de octubre de 1811, y posteriormente, una vez que se deshizo de su rival político Fulgencio Yegros, para proclamarse Dictador, un 12 de octubre de 1814. Estas posiciones contradictorias, que normalmente son evitadas u omitidas cuando se expone la historiografía en los manuales al uso de todos los niveles académicos, son sin embargo un punto de partida ineludible y esencial a la propia disciplina historiográfica; las propias concepciones ideológicas convierten, literalmente, a la Historia no en una disciplina científica, sino en un verdadero campo de batalla ideológico. 


\section{Alternativas sobre el Bicentenario de Paraguay}

Una de las problemáticas habituales a la hora de exponer los procesos de las independencias hispanoamericanas es el enfoque ideológico y las fuentes doctrinales que condujeron al proceso emancipador. Es moneda común atribuir a Jean Jacques Rousseau y su El Contrato Social el origen de tales independencias, idea ocultada bajo la denominada "máscara de Fernando" (Lynch, 2010, p. 64), también denominada "la máscara del juramento de fidelidad a Fernando VII" (Benítez, 1984, p. 37), o "la farsa de gobernar en nombre de Fernando VII" (Cardozo, 2010, p. 76), que la mayoría de historiadores "interpretaron como un hábil y cínico disfraz para enmascarar sus propios objetivos políticos" (Stoetzer, 1982, p. 412-13). Idea que, sin embargo, no aclara cómo fue posible que en todos los lugares del Imperio Español en América, el proceso emancipador comenzase reasumiendo la soberanía del Rey de España Fernando VII.

Esta peculiar situación obliga a clasificar las diferentes alternativas a la hora de comprender las relaciones existentes entre España y América, una clasificación inspirada en la obra de Gustavo Bueno (Bueno, 2000), pensado en particular para analizar la independencia y formación de la República del Paraguay. Este acontecimiento histórico cabe interpretarlo desde diversas perspectivas, siendo algo que involucró tanto a España como a América. Desde esa idea inicial, cabe establecer un esquema de cuatro alternativas de relaciones entre España y América, aplicado a nuestro caso particular:

Ni América está en España, ni España está en América. Desde esta perspectiva, la independencia americana habría sido un trasunto del avance de "la Modernidad" que puso fin al Antiguo Régimen, siendo España e Hispanoamérica una mera "periferia" de lo sucedido en Estados Unidos a partir de 1776 y en Francia en 1789. La influencia ideológica fundamental desde esta perspectiva es la filosofía ilustrada, y más concretamente EI Contrato Social de Rousseau. Un ejemplo de esta posición lo tenemos en Justo Pastor Benítez (Benítez, 1984, pp. 73-7) quien compara al Supremo Dictador con Robespierre, afirmando que ambos revolucionarios seguían la influencia de Rousseau. También cabe incluir aquí a Richard Alan White, quien sitúa la ideología del Doctor Francia con referentes idénticos, y considera al Imperio Español una "periferia" del "centro" europeo del capitalismo mundial, siendo Hispanoamérica más "periferia" aún si cabe: "la razón principal de la oposición unificada a las pretensiones porteñas fue la posición periférica del Paraguay en el imperio español, en un callejón sin salida político y económico" (White, 1989, p. 39).

América está en España y España no está en América. Se trata de la perspectiva "indigenista", que considera que América es una realidad preexistente a la "invasión" de la misma por los españoles europeos. Desde esta perspectiva, la emancipación americana sería una liberación de una cultura europea postiza. Tal es el caso de la tesis sostenida por Anastasio 


\section{Artículos de colaboradores extranjeros}

Rolón Medina, quien considera que el auténtico prócer de la independencia paraguaya sería el cacique Lambaré, "el no dominado", quien habría liderado la resistencia de los guaraníes frente a los españoles, y que al morir su espíritu habría quedado latente en el pueblo paraguayo, emergiendo en momentos tales como la revolución del 14 y 15 de Mayo de 1811:

"Ese espíritu cuya santa e impotente indignación saltara del pecho del noble indígena por la boca de una negra herida, inflamó a los criollos y los lanzó a la Revolución de los Comuneros en 1722, en defensa de los derechos del pueblo y de los ideales humanos.

Ese mismo espíritu del inmortal cacique ha animado a la hueste de Gamarra, Cabañas y Yegros en 1810 y comienzos del 11, para enfrentar y reducir a los porteños en las célebres batallas de Paraguarí y Tacuary. El grito de nuestra independencia, lanzado días después, respondía a un mandato de ultratumba que se apoderó de nuestros próceres y les infundió el designio emancipador de Mayo.

El fantasma del taciturno cacique, es algo serio. Su espíritu no se apartó de las bravas legiones de Solano López, cuando este glorioso luchador se alzó con su pueblo y se convirtió en el sustentáculo del principio de autodeterminación, en defensa del derecho y en resguardo del equilibrio de las naciones del Continente, retoños todos del secular tronco guaraní." (Rolón Medina, 1968, p. 134).

España está en América, pero América no está en España. Desde esta perspectiva, América sería una realidad previa, con sus propios estados ya existentes antes de la llegada de los españoles, que una vez alcanzado cierto nivel de civilización, se independizaría en virtud de la teoría católica del poder, de la democracia cristiana, aquélla que en el siglo XVII autores como el jesuita Francisco Suárez (1548-1617) explicaron como contrapunto al absolutismo de la reforma protestante: según esta teoría, la soberanía proviene de Dios pero reside en la sociedad civil, que es la que da asentimiento a los monarcas.

Así, cuando se produjo el secuestro de la soberanía en 1808 al ser invadida España por Napoleón, en América se formaron juntas en defensa de los derechos de Fernando VII, asumiendo así la soberanía cedida en su día al monarca español. Con el paso del tiempo, estas juntas se proclamarían independientes y América podría ya desarrollar su vida histórica al margen de España. Este caso lo ejemplifica no sólo el citado Carlos Stoetzer (Stoetzer, 1982), sino especialmente Efraím Cardozo, quien señala que el Doctor Francia había estudiado en la Universidad de Córdoba al jesuita español Francisco Suárez, el "Doctor Eximio", quien en sus obras De legibus (1612) y Defensio fidei (1613), afirma que la soberanía popular es originaria — proviene de Dios, afirma-, no es enajenable y otorga derecho al pueblo a rebelarse contra la tiranía de un monarca ilegítimo, en este caso José I Bonaparte. Una vez que el rey legítimo, Fernando VII, había sido secuestrado, el poder retornaba al pueblo según el pactum translationis enunciado por Suárez: 
"Con la abdicación e impedimento de Fernando VII, rey legítimo que contaba con el consentimiento de toda la nación americana para la cual la monarquía era el nexo de unión con la metrópoli, y la institución, por acto unilateral de Napoleón, de una nueva dinastía, el poder supremo quedaba vacante. Los pueblos americanos no habían concurrido a la formación de la nueva dinastía, ilegítima, usurpadora, intrusa. La soberanía debía retornar al pueblo, y en el caso de América, tenía el mismo derecho que el de la península para reajustar las nuevas estructuras de su organización política e instituir las nuevas autoridades." (Cardozo, 2009, p. 132).

América está en España y España está en América. Esta perspectiva se basa en parte en las ideas de Gustavo Bueno (Bueno, 1999). De alguna manera, este posicionamiento recoge a los tres anteriores y los reformula. Así, el 14 y 15 de Mayo de 1811 se produjo en Asunción una revolución que formó una junta en nombre de la soberanía de Fernando VII, por lo que en rigor no supone una proclamación de independencia. Asimismo, cuando el 12 de Octubre de 1813 se proclama la República del Paraguay, se realiza desde una perspectiva que pretende abarcar a todo el continente americano, no a una república diferenciada de otras ya existentes.

Gustavo Bueno señala con acierto que, en el momento que el poder español caducaba en América, las manifestaciones de unidad continental se hicieron más patentes que nunca:

"la 'dispersión' de la globalidad de la América Hispana durante los siglos del Imperio, comenzó a ceder en el momento en el cual el núcleo de ese Imperio fue descabezado por la invasión napoleónica. La dispersión sólo se transformó en cohesión en los cortos años de la emancipación." (Bueno, 1999, p. 384).

En el caso paraguayo, la idea inspiradora de esta perspectiva era sin lugar a dudas la antigua Provincia Gigante de Indias, desde la que se había realizado la conquista americana hasta que en 1617 se dividió en las provincias de Paraguay y Buenos Aires. Así, la ciudad de Asunción, en virtud de las necesidades de esta expansión, se habría convertido en Madre de Ciudades; además, con la emancipación del siglo XIX, en Cuna de la Libertad Americana; de ahí el significado de la fecha del 12 de Octubre, como efeméride del descubrimiento de América, elegida por el Doctor Francia para proclamar la independencia de la República del Paraguay. Al fin y al cabo, el paraguayo ha...

"...nacido en el trópico de la unión de españoles y guaraníes, dos razas de guerreros, que salvaron en el Guayrá las marcas de la hispanidad. La historia paraguaya está forjada en el crisol de dos choques: fuerzas hispanas del sur y lusitanas del este; fuerzas españolas del sureste y fuerzas españolas del noroeste. De este doble juego surge la nacionalidad guaraní como una potente creación histórico-geográfica." (Chaves, 1946, p. 212). 


\section{Artículos de colaboradores extranjeros}

\section{Y como confirma Efraím Cardozo:}

"La conciencia y el orgullo de haber sido la Provincia Gigante de Indias y de que el nombre paraguayo estampara su sello denominador y civilizador sobre las más vastas tierras del continente sudamericano, fue estímulo para sobrellevar infortunios para aspirar a grandezas de otro orden, que no fueran meramente materiales o geográficas." (Cardozo, 1996, p. 22).

De hecho, sólo en 1842, ya fallecido el Doctor Francia y ante la imposibilidad de realizar el proyecto de unidad continental, Carlos Antonio López proclamó formalmente la independencia de la República del Paraguay en los términos actuales, como estado ya definido frente a otros como Argentina, Brasil o Bolivia. En este caso, el fundamento esgrimido por el Doctor Francia, ya desde el Cabildo abierto convocado en Asunción el 24 de julio de 1810, para debatir sobre la revolución del 25 de Mayo en Buenos Aires, era que "el gobierno español ha caducado en el continente" (Chaves, 1946, p. 80), a causa de haber sido depuesto el rey legítimo y haber entregado a Napoleón América las autoridades españolas responsables de su no enajenación.

Sin embargo, esta "libertad" de la que recientemente se han cumplido doscientos años, no suponía romper los lazos con España, puesto que de alguna manera las relaciones entre España y América se han mantenido e incluso incrementado por los vínculos históricos, culturales e idiomáticos que permiten hablar de una Hispanidad instalada en ambos hemisferios.

\section{LA HISTORIA COMO CIENCIA HUMANA}

\section{LAS METODOLOGÍAs a Y $\beta$ OPERATORIAS}

En el año 2013, el verdadero bicentenario de la independencia paraguaya a decir de Richard Allan White, se hizo pública una noticia sorprendente: la controversia producida, en el mes de junio, a raíz de las declaraciones del entonces Presidente de la República, Federico Franco, por instigación del investigador Tito Aranda, en las que afirmaba que debía retirarse el cuadro de Guillermo Da Re, Intimación a Velasco, del Palacio Presidencial, afirmando que en lugar de representar la noche del 14 y 15 de mayo de 1811, en realidad plasma el 24 y 25 de mayo de 1810 de Buenos Aires; pese a que Federico Franco no cumplió con su amenaza de retirar el lienzo, ordenó cubrir la pintura que figura en el Palacio de Gobierno.

La decisión del Presidente fue objeto de polémica entre varios estudiosos aquellos días; se especuló con la idea de que el lienzo no tenía por qué reflejar con exactitud la realidad histórica, pues no había pintores en la provincia del Paraguay para retratar el momento justo de la capitulación del Gobernador Bernardo de Velasco. Pero esa cuestión, aireada casi como un mero artificio para que todo siguiera encajando en un lecho de Procusto historiográfico que 
ya no se sostiene de manera alguna, es meramente ornamental; tampoco había pintores en la toma de Granada por los Reyes Católicos, el 2 de enero de 1492, ni los había en el Monasterio de la Rábida cuando Cristóbal Colón expuso su plan de viaje hacia Asia (que culminaría en el descubrimiento de América), y ello no impidió que varios pintores españoles del siglo XIX plasmasen verosímilmente estos hechos.

Si como dice Aristóteles en su Poética, la poesía (las artes diríamos hoy), es más filosófica que la Historia, porque nos habla de lo que pudo pasar (Aristóteles, 1988), hemos de analizar la pintura de Guillermo Da Re sobre el 14 y 15 de mayo de 1811 como una obra verosímil de lo que pudo pasar en ese momento, pero que a su vez incluye la propia interpretación del pintor. Este artista participó además en la elaboración de las iconografías del centenario de la revolución de Buenos Aires, en 1910, y sin duda alguna debía arrastrar mucha influencia en ese aspecto (de hecho, otra obra muy similar a la citada se encuentra en la Casa Rosada de Buenos Aires).

Y es que la pintura representa una reunión donde una silla ha sido arrojada al suelo, mientras alguien conmina a quien ha perdido su asiento a abandonar el lugar. Se sospecha que la escena representa en realidad al criollo Cornelio Saavedra invitando al virrey Baltasar Hidalgo de Cisneros a abandonar la reunión, hecho que precederá a la constitución de la Junta en nombre de la soberanía de Fernando VII, el 25 de Mayo en Buenos Aires. Escena que parece encajar con el cuadro de Da Re, mientras que los hechos del 14 y 15 de Mayo de 1811 en Asunción, relatados por el teniente de dragones portugués José de Abreu (Vittone, 1960), hablan de un asedio de los revolucionarios al palacio de gobierno de Bernardo de Velasco, quien al finalizar la noche decide entregar el poder para integrar, junto al Doctor Francia y el capitán español Juan Valeriano Zeballos, una Junta gubernativa en nombre de Fernando VII. Algo diametralmente opuesto a lo que nos muestra la pintura citada.

En cualquier caso, esta polémica iconográfica no haría más que confirmar que la independencia del Paraguay como "primera República del Sud", orientada inicialmente para aglutinar en torno a sí a todo el continente americano (de ahí su proclamación el 12 de Octubre, en referencia al descubrimiento de América), habría tenido lugar en 1813, y quienes insisten en defender el 14 y 15 de Mayo de 1811 como fecha de la independencia no sólo carecen de argumentos historiográficos firmes, sino que además siguen una idea impuesta por Buenos Aires tras la Guerra de la Triple Alianza. Festejar el 2011 como bicentenario del Paraguay es en definitiva asumir unos fastos impuestos e interpretados por Argentina.

Hay que señalar, en consecuencia, que la Historia positiva no se caracteriza por el estudio del "pasado", puesto que tal período de la Historia no existe desde nuestro presente (no podemos influir sobre algo que ya no existe), sino por el análisis de reliquias y relatos que se refieren al pretérito. Reliquias que se refieren a distintas posiciones e ideologías, que no son neutrales ellas 


\section{Artículos de colaboradores extranjeros}

mismas. De ahí que la Historia, al igual que otras ciencias humanas, esté dividida en distintas metodologías que impiden el cierre de una categoría científica como podrían ser las Matemáticas, la Biología o la Física. Si desde la perspectiva de la Gnoseología materialista se identifican las ciencias naturales, las ciencias en sentido fuerte como aquellas que neutralizan las operaciones de los sujetos, para ofrecernos como resultado final verdades que desbordan esas operaciones, cabría señalar que en las ciencias humanas existen en principio metodologías que son dependientes de las operaciones del sujeto gnoseológico (metodologías $\beta$ ) y metodologías donde se segrega ese sujeto gnoseológico (metodologías a) llegando como caso límite al grado más próximo de la ciencia natural (Bueno, 1978a y 1978b).

Existen dos casos extremos dentro de estas metodologías: el $\mathbf{a}_{1}$, donde la ciencia humana prácticamente se convierte en ciencia natural, y el $\beta_{2}$, donde se supone que lo que impera es la praxis humana, esto es, la práctica casi tecnológica, en la que los sujetos interactúan entre sí en el presente (al contrario de lo que sucede en la Historia, donde unos sujetos desde el presente han de desentrañar lo que les sucedió a otros sujetos que ya no se encuentran entre nosotros, en el pasado).

Tomando esta perspectiva, cabría clasificar dentro de los distintos estados por los que pasaría la Historia las distintas metodologías utilizadas para entender el bicentenario de la independencia del Paraguay:

Metodologías $\boldsymbol{a}_{\mathbf{1}}$ : Este ejemplo aparece en la obra literaria de Augusto Roa Bastos, Yo el Supremo (1974), que pese a no ser una obra de historiografía simula un congreso de historiadores, donde autores reales como Julio César Chaves o Marco Antonio Laconich "debaten" a través de sus textos cruzados sobre el lugar donde se encuentran los restos del Doctor Francia (hoy diríamos que se usarían pruebas de ADN para demostrar su identidad). Dice al comienzo de su epílogo:

“El 31 de enero de 1961, una circular oficial convocó a los historiadores nacionales a un cónclave con el fin de 'iniciar las gestiones tendientes a recuperar los restos mortales del Supremo Dictador y restituir al patrimonio nacional esas sagradas reliquias'. La convocatoria se hizo extensiva a la ciudadanía exhortándola a colaborar en la patriótica Cruzada de reconquistar tanto el sepulcro del Fundador de la República como sus restos, desaparecidos, aventados por anónimos profanadores, los enemigos del Perpetuo Dictador. Los ecos de la convocatoria llegan a los más apartados confines del país. Al igual que en otros momentos cruciales de la vida nacional la ciudadanía toda se pone de pie como un solo hombre y responde a una sola voz. La única disonancia en esta afirmación plebiscitaria es joh sorpresa! la de los especialistas, cronistas y folletinistas de la historia paraguaya. Una repentina e inesperada incertidumbre parece ensombrecer la conciencia historiográfica nacional acerca de cuál puede ser el único y auténtico cráneo de El Supremo. Las opiniones se dividen; los 
historiadores se contradicen, discuten, disputan ardorosa, vocingleramente. Es que -como cumpliéndose otra de las predicciones de El Supremoesta iniciativa de unión nacional se convierte en terreno donde apunta el brote de una diminuta guerra civil, afortunadamente incruenta, puesto que se trata sólo de un enfrentamiento'papelario'." (Roa Bastos, 2005, p. 597).

Metodologías $a_{2}$. Abordan la cuestión histórica desde una perspectiva que envuelve y determina decisivamente las acciones de los sujetos históricos. Se bifurcan en dos tipos:

I- $a_{2:}$ Métodos estadísticos, donde habría que incluir la denominada "Historia cuantitativa".

II- $\mathrm{a}_{2}$ : Sería una posición propia de historiadores que asumen el determinismo economicista propio del materialismo histórico más vulgar. Aderezado de la teoría económica de la dependencia tan de moda en la Guerra Fría, que distingue entre un "centro" del modo de producción capitalista y una "periferia" de explotados, donde se encontraría Hispanoamérica. Tal es el caso, para ambas metodologías, del citado Richard Alan White, quien al comienzo de su obra parte de una fe analítica que en ningún momento justifica y que supone como cuestión de hecho: que en el tránsito del dominio sobre América de dos sistemas coloniales y opresivos, uno el del anacrónico y feudal Imperio Español, a su vez dependiente del otro, el sistema capitalista mundial, el Paraguay se mantuvo como país independiente de la explotación económica mundial:

"Las instituciones políticas y económicas que gobernaron la América española durante la era colonial, fueron establecidas para enriquecer a España, no para promover la prosperidad de América. El oro y la plata del Nuevo Mundo, así como otros productos americanos, solventaron siglos de participación española en las luchas por el poder en Europa. España propiamente dicha, empero, era una colonia económica de los países más industrializados de Europa. Consecuentemente, para cubrir su déficit crónico en la balanza de pagos, España gastó la mayoría de sus riquezas provenientes del Nuevo Mundo en artículos manufacturados importados. De este modo, la riqueza de América española sirvió en último término para financiar la industrialización de las naciones del Norte de Europa. Al lograr la independencia y romper sus vínculos políticos y económicos con España, las nacientes naciones latinoamericanas desplazaron su dependencia económica de España a las naciones más industrializadas de Europa, iniciando con ello la era neocolonial." (White, 1989, p. 1)

También señala White que el frente común entre criollos y españoles en la provincia del Paraguay (donde habría que incluir no sólo las resoluciones adoptadas por el Cabildo de Asunción el 24 de julio de 1810, sino también la presencia del capitán español Juan Valeriano Zeballos entre los revolucionarios del 14 y 15 de Mayo de 1811), frente a la revolución del 25 de Mayo de 1810 


\section{Artículos de colaboradores extranjeros}

en Buenos Aires, se explica por el papel que jugaba la provincia del Paraguay como periferia de la región:

"la razón principal de la oposición unificada a las pretensiones porteñas fue la posición periférica del Paraguay en el imperio español, en un callejón sin salida político y económico. No había una clase criolla poderosa o bien atrincherada, cuya posición socioeconómica estuviera basada ventajosamente o vinculada a la estructura colonial." (White, 1989, p. 39).

Asimismo, en nota al pie reafirma esta idea señalando que:

"En general, cuanto más alejada estaba una colonia del centro del imperio, tanto más era explotada. El progreso de los movimientos de liberación sudamericanos, comenzando en las periferias del imperio y prosiguiendo gradualmente hacia el centro militar y administrativo (Perú), dramáticamente ilustra este principio." (White, 1989, p. 39).

Es más, literalmente Alan White afirma que, una vez eliminada la oligarquía como clase dominante en Paraguay, Francia no permitía que los términos del intercambio comercial paraguayo fueran determinados por precios regionales del mercado mundial. En lugar de ello, "organizó el intercambio de los productos nativos del Paraguay", definidos explícitamente por el Dictador como "el producto de su trabajo sobre su costo efectivo de producción, o valor del trabajo, en relación con la utilidad o valor de uso, de las importaciones" (White, 1989, p. 185). Con esta dialéctica entre el centro y la periferia, extraída del marxismo más vulgarizado de su época, pareciera que, en lugar de hablar del Doctor Francia, un español americano del siglo XIX, estuviera hablando el señor White, poseído de un curioso anacronismo, de un Che Guevara o un Fidel Castro.

Metodologías $\beta_{1}$ : Son las propiamente genuinas de las ciencias humanas, puesto que aun presentando resultados objetivos y que perviven a los sujetos que las produjeron, dependen de las operaciones de dichos sujetos para ser comprendidas. Se bifurcan a su vez en dos clases:

Metodologías I- $\beta_{1}$ : Verum est factum, la metodología propia de la Historia fenoménica. En ella se encuentran las reliquias y documentos sobre la independencia americana, desde los autos del 14 y 15 de Mayo de 1811 en Asunción, donde se describe la revolución que depone al gobernador español Bernardo de Velasco, hasta la declaración formal de independencia de la República del Paraguay dentro del Río de la Plata, realizada por Carlos Antonio López el 25 de Noviembre de 1842, sin olvidar hitos como la Nota del 20 de Julio de 1811, primer documento donde se menciona la unidad americana, y la proclamación de la República del Paraguay, "la primera República del Sud", el 12 de Octubre de 1813. Y también, cómo no, el famoso cuadro de Guillermo Da Re donde se representa, según afirman algunos, el 25 de Mayo de 1810 en Buenos Aires, y que sin embargo durante un siglo fue considerado 
el verdadero retrato de la independencia paraguaya, tanto como para aparecer en el reverso de los billetes de diez mil guaraníes. Reliquias donde se aprecia la teoría de la democracia cristiana de Francisco Suárez y la recuperación del poder para el pueblo una vez desaparecida la autoridad del Rey de España, según la teoría del pactum translationis.

Documentos que, como tales, no aparecen como hechos meramente descritos por los historiadores, sino que éstos los extractan y encajan en particulares lechos de Procusto, para hacerles decir lo que ellos ya pretenden señalar de antemano. Es particularmente curioso cómo esa apelación a los hechos y los documentos, como si por sí mismos dijeran algo, se eclipsa cuando se trata de casos como el de la independencia formal de la República del Paraguay, que fue proclamada formalmente hasta el 25 de Noviembre de 1842. Si tales historiadores fueran coherentes, tendrían que trasladar la fecha de la independencia formal, según los documentos, al citado año 1842...

Metodologías II- $\beta_{1}$ : Aquí incluiremos la denominada "teoría de juegos", iniciada en Estados Unidos en el Instituto RAND (Research And Development) durante los tiempos de la Guerra Fría, que intenta expresar mediante métodos matemáticos el comportamiento de ciertos grupos humanos, aunque sin prescindir de una conducta humana que en ciertos casos es impredecible. En el caso histórico que nos ocupa, no cabe duda que las relaciones diplomáticas que la naciente República del Paraguay hubo de establecer con Buenos Aires y otros centros de poder que "querían lo mismo", esto es, la unidad continental, el cálculo de los movimientos del enemigo resultaba crucial. Nadie en Buenos Aires, y menos el diplomático Nicolás Herrera, enviado a Asunción para lograr que la provincia enviase diputados al próximo congreso de las Provincias Unidas del Río de la Plata, suponía que el Doctor Francia proclamaría la independencia americana un 12 de Octubre, dejándoles sin alianza ni tratado alguno. Así lo manifiesta airadamente en un oficio enviado a Buenos Aires con fecha 7 de Noviembre de 1813:

"El ha persuadido a los paraguayos:

Que la Provincia [del Paraguay por sí] sola es un imperio sin igual.

Que Buenos Aires la adula y linsojea porque la necesita.

Que con el pretexto de la Unión, [Buenos Aires] trata de esclavizar el continente [sudamericano].

Que los pueblos [del Virreinato] han sido violentados para el envío de sus representantes [al Congreso de Buenos Aires]. [...]

En el sobre del oficio que incluyo, se titula el Paraguay: La primera República del Sud, suponiéndose el único pueblo libre, con otras puerilidades que manifiestan el desorden de las cabezas que [aquí] mandan..." (Vázquez, 1975, p. 99).

Metodologías $\beta_{2}$ : A este caso extremo corresponde sin duda la denominada "historiografía del presente", esto es, el estudio de diversas posiciones históricas sobre los bicentenarios que a día de hoy mantienen 


\section{Artículos de colaboradores extranjeros}

historiadoresypolíticos, en confrontación con quienes, como es el caso, intentan desentrañar todas estas ideologías involucradas en la historiografía. Aquí nos situaríamos en la perspectiva de las diversas interpretaciones, polémicas entre sí, que se han ofrecido sobre el bicentenario de la independencia del Paraguay, desde la que considera la independencia americana como resultado de las teorías de Rousseau sobre el contrato social, pasando por el indigenismo que postula la presencia española en América como una imposición postiza y ajena al verdadero ser americano, hasta interpretaciones más habituales ofrecidas en la actualidad para entender el hecho histórico de la independencia.

En consecuencia, en esta metodología habría que incluir a todos aquellos historiadores que, pese a que reconocen que el 14 y 15 de mayo de 1811 no se produjo la independencia del Paraguay, sino la formación de una junta en defensa de los derechos del Rey de España Fernando VII, han alimentado el partidismo ideológico distorsiona la realidad de las reliquias y relatos sobre el tema, siendo partícipes acríticos de los fastos del bicentenario celebrados en 2011, o a lo sumo considerándolos como parte del "proceso" de la independencia. En este caso, la historiografía se convierte en pura lucha ideológica.

\section{CONCLUSIÓN}

Como hemos probado, la historiografía sobre el bicentenario paraguayo no constituye una ciencia donde todas las posiciones sean uniformes (ello conduciría únicamente al dogmatismo), sino que el campo de la historiografía semeja un verdadero campo de batalla ideológico, donde las posiciones son muchas veces dispares o diametralmente opuestas. De hecho, pese a que la idea "procesual" de revoluciones, independencias y ratificaciones sea para nosotros incorrecta, sí que es verdad, como hemos señalado, que la independencia americana no condujo inmediatamente a las repúblicas actuales, sino que un movimiento no concertado de diferentes juntas de gobierno condujo a la desaparición del poder español en América y finalmente a la disgregación de los virreinatos existentes en distintas naciones. Como señala John Lynch:

"El Estado borbónico en Hispanoamérica no fue sucedido inmediatamente por una serie de nuevos Estados nacionales. Hubo una etapa intermedia en la cual los ejércitos libertadores o las bandas de los caudillos desafiaron primero, y luego destruyeron, el poder político y militar de España. En algunos casos fue un proceso largo y llevó aparejada la creación de Estados rudimentarios durante la guerra, los cuales podían recaudar impuestos y reclutar tropas. Pero tales Estados no eran necesariamente naciones." (Lynch, 2010, p. 335).

No obstante, no fue sino con la experiencia compartida tras varias décadas de vida independiente, así como conflictos externos que asociaron nación, 
identidad, territorio e independencia, como se conformó un concepto político de nación en Hispanoamérica. Ejemplos de ello son conflictos tales como las guerras de los Estados Unidos con Méjico, o las diversas guerras entre las naciones hispanoamericanas por fijar los límites y fronteras existentes entre ellas. En el caso del Paraguay, la existencia de un enemigo común, ya fuera en la Guerra de la Triple Alianza (1864-1870), considerada como "Epopeya Nacional", o la Guerra del Chaco (1932-1935), fue lo que permitió sentenciar la existencia de una nación paraguaya y sus límites respecto a terceros países, como Bolivia en este segundo caso:

"Incluso después de obtener la independencia, la creación de Estados nuevos precedió a la formación de naciones. Porque el crecimiento de la conciencia nacional fue lento y parcial, además de encontrar muchos impedimentos. Sin embargo, había factores nuevos que favorecían un concepto más positivo de la nación. La guerra revolucionaria fue en sí misma una causa noble, por la cual los ejércitos insurgentes libraron batallas gloriosas y el pueblo, aunque a regañadientes, hizo grandes sacrificios. Los hispanoamericanos tenían ahora su propio pasado heroico, su propio honor militar, sus propios mitos revolucionarios. [...] Se vieron obligados, además, a iniciar relaciones con otros Estados, en Europa y en América, proceso que los hizo más conscientes de su propia nacionalidad y más expuestos a las rivalidades nacionales. Algunos de los nuevos Estados -Uruguay y Boliviaencontraron su verdadera identidad precisamente en los conflictos con sus vecinos americanos." (Lynch, 2010, p. 335).

Las generaciones de historiadores posteriores a la Guerra de la Triple Alianza, reconstruyeron toda la historia desde la revolución del 14 y 15 de mayo de 1811 como surgimiento de la nacionalidad paraguaya y no como proyecto de unidad continental. Precisamente, varios de estos autores estarían involucrados en cuestiones de suma importancia para la nación paraguaya, como la definición de los límites con Bolivia, situación polémica que desembocaría en la Guerra del Chaco. Por ejemplo, Justo Pastor Benítez interpretó en 1937 al Doctor Francia no como un prócer a la altura de un Bolívar o un San Martín en sus pretensiones, sino simplemente como fundador de la actual nacionalidad paraguaya: "Para la creación del Paraguay, preexistían factores territoriales, raciales, idiomáticos y la tradición cívica de los Comuneros. La tarea consistió en organizar con esos factores un Estado, y hacer que tal Estado fuera una república, democrática, igualitaria" (Benítez, 1984, p. 186).

Al contrario de naciones europeas como España, Francia o Inglaterra, donde siglos de experiencias comunes previas a las naciones modernas permitieron el paso prácticamente directo de una nación histórica a una nación política, las naciones americanas hubieron de nacer fruto de las experiencias fracasadas de unidad continental que Bolívar, San Martín o el Doctor Francia intentaron poner sobre el terreno, dejando un mosaico de fronteras artificiosas hasta entonces nunca trazadas como tales. La descomposición de la Monarquía 


\section{Artículos de colaboradores extranjeros}

Hispánica y del Imperio Español, y con ella de muchos de los referentes que mantenían esa unidad, fueron causas inmediatas de ello.

Sin embargo, la paradoja resultante es que, pese a la descomposición política y atomización del continente americano, la identidad común hispanoamericana se vio poderosamente reforzada, por encima de indigenismos y particularismos varios. El idioma común de Hispanoamérica, el español, se mantuvo como ese referente que permite la comunicación por encima de diferencias nacionales a veces muy enconadas. En un mundo en el que, en contra de Fukuyama, la Historia Universal no ha finalizado sino que ha comenzado de manera efectiva, gracias a poderosas herramientas de comunicación global como internet o la televisión en directo, no es desdeñable la incidencia que puedan alcanzar plataformas tales como la actual comunidad hispánica de naciones, cuyo status quo es susceptible de transformación e incluso de jugar un papel histórico de importancia en un futuro no muy lejano.

En cualquier caso, la mera invocación a una efeméride o efemérides diversas no agota un tema tan rico y tan importante para la Historia común de España e Hispanoamérica, como es el proceso de la independencia y formación de las repúblicas hispanoamericanas y sus relaciones entre sí a lo largo de la Historia. Una Historia que ha dejado, en el caso de Paraguay, un presente poco deseable, donde el país gravita en torno a Brasil y Argentina, que ejercen el papel de dos fuerzas que, aplicadas desde el mismo punto, arrastran al "Corazón de América" con una resultante incierta, pero que no sirve de excusa para interpretar la primera experiencia de unidad continental en la independencia de una pobre nación, autárquica y desentendida del mundo, por voluntad de una suerte de hombre providencial o, para otros, un mero tirano.

\section{REFERENCIAS}

Alan White, R. (1989). La primera revolución popular en América. Paraguay 1810-1840. Asunción: Carlos Schaumann.

Aristóteles (1988). Poética. Madrid: Gredos.

Benítez, J. P. (1984). La vida solitaria del Dr. José Gaspar de Francia. Dictador del Paraguay. Asunción: Carlos Schaumann.

Bueno, G. (1999). España frente a Europa. Barcelona: Alba Editorial.

Bueno, G. (2000). Televisión: Apariencia y Verdad. Barcelona: Gedisa.

Bueno, G. (1978a), Reliquias y relatos: construcción del concepto de "Historia fenoménica", El Basilisco, № 1, 5.16.

Bueno, G. (1978b), En torno al concepto de "Ciencias humanas". La distinción entre metodologías $\boldsymbol{\alpha}$-operatorias y $\beta$-operatorias, El Basilisco, $N^{\circ} 2,12.46$.

Caballero Campos, H. (2010), Proceso de la Independencia Paraguaya. 17801813. Asunción: El Lector. 
Cardozo, E. (1954). La princesa Carlota Joaquina y la independencia del Paraguay, Revista de Indias, No 57-58, 359.383.

Cardozo, E. (1996). El Paraguay colonial. Las raíces de la nacionalidad. Asunción: Editorial El Lector.

Cardozo, E. (2009). Afinidades entre el Paraguay y la Banda Oriental en 1811. La Proclamación de la República del Paraguay en 1813. Tensiones en la ideología de la Revolución emancipadora. Asunción: Servilibro.

Chaves, J. C. (1946). El Supremo Dictador. Biografía de José Gaspar de Francia [1942]. Buenos Aires: Editorial Ayacucho.

Chaves, J. C. (2010), La Revolución Paraguaya de la independencia. Biografía de los Próceres. Asunción: Intercontinental Editora.

Garay, B. (1896), Compendio elemental de Historia del Paraguay. Madrid: Librería y Casa Editora A. de Uribe y Cía.

Graty, A. M. (1862), La República del Paraguay. Besanzon: Imprenta de José Jacquin.

López, C. A. (1848), Decreto de 7 de Octubre de 1848. El Paraguayo Independiente, $N^{\circ} 3.4$.

Lynch, J. (2010). Las revoluciones hispanoamericanas 1808-1826. Barcelona: Ariel.

Roa Bastos, A. (2005). Yo el Supremo. Madrid: Cátedra.

Rolón Medina, A. (1968). Raíces de la nación paraguaya. Asunción: Imprenta de la Humanidad.

Scavone Yegros, R. (2011). La Declaración de la Independencia del Paraguay. Servilibro: Asunción.

Stoetzer, C. (1982). Las raíces escolásticas de la emancipación de la América Española [1979]. Madrid: Centro de Estudios Constitucionales.

Vázquez, J. A. (1975). El Doctor Francia visto y oído por sus contemporáneos. Buenos Aires: Eudeba.

Vittone, L. (1960). El Paraguay en la lucha por su independencia. Asunción: Imp. Militar.

\section{Cómo citar este artículo:}

Rodríguez Pardo, J.M.. (2016). El Bicentenario de Paraguay como ejemplo de la didáctica de la Historia. Revista Científica Estudios e Investigaciones, Vol. 5, pp. 103-121. 